\title{
Gellan Gum Immobilized Anticancer Drugs and Gold Nanoparticles in Nanomedicine
}

\author{
Sarkyt E Kudaibergenov ${ }^{1,2 *}$, Shimei Xü ${ }^{3}$, Gulnur S Tatykhanova ${ }^{1,2}$ and Gulnar M Kudaibergenova ${ }^{2}$ \\ ${ }^{1}$ Institute of Polymer Materials and Technology, Republic of Kazakhstan \\ ${ }^{2}$ Laboratory of Engineering, K.I. Satpayev Kazakh National Research Technical University, Republic of Kazakhstan \\ ${ }^{3}$ College of Chemistry, Sichuan University, China
}

Submission: February 18, 2019; Published: February 25, 2019

*Corresponding author: Sarkyt E Kudaibergenov, Institute of Polymer Materials and Technology, Republic of Kazakhstan

\begin{abstract}
This review is devoted to recent progress in the design of anticancer drug delivery systems with participation of unique polysaccharide gellan gum. At first a brief literature survey on conformational and phase behavior of gellan gum as a function of external stimuli, such as temperature, $\mathrm{pH}$, salt addition etc. is presented. Then the immobilization protocol of anticancer drugs and gold nanoparticles within gellanbased hydrogel matrix is discussed. Release of anticancer drugs from gellan gel matrix to outer solution is considered. Cytotoxicity of gellan gum-immobilized gold nanoparticles together with their anticancer activity is summarized.

Keywords: Gellan gum; Coil-helix transition; Hydrogel; Anticancer drugs; Gold nanoparticles; Cytotoxicity; Anticancer activity

Abbreviations: GG: Gellan Gum; EOR: Enhanced Oil Recovery; AgNPs: Silver Nanoparticles; AuNPs: Gold Nanoparticles, AuNR: Gold Nanorods, DDS: Drug Delivery System; PCT: Paclitaxel; Ge-Pred NHs: Gellan-Prednisolone Nanohydrogel; PCT Ge-Pred NHs: Gellan-Prednisolone-Paclitaxel Nanohydrogel; GG-AuNPs: AuNPs Covered by Gellan Gum; GG-AgNPs: AgNPs Covered by Gellan Gum; DOX: Doxorubicin Hydrochloride; SL: Sophorolipid; NIR: Near-IR; PPTT: Plasmonic Photothermal Therapy; CTAB: Cetyltrimethylammonium Bromide; LBL: Layer-By-Layer; SaOS-2: Sarcoma Osteogenic; PVCL: Poly(vinylcaprolactame); TNBC: Triple Negative Breast Cancer
\end{abstract}

\section{Introduction}

Over the past few decades, microbial polysaccharides have been under intense investigation due to their advantageous physicochemical properties. Currently, one of the most widely studied and comprehensively described member of this group is gellan a linear polymer produced by Sphingomonas elodea consisting of a tetrasaccharide repeating unit of 1,3-linked $\beta$-Dglucose, 1,4-linked $\beta$-D-glucoronic acid, 1,4-linked $\beta$-D-glucose, and 1,4-linked $\alpha$-L-rhamnose [1] (Figure 1). Fermentative production and manufacturing of gellan on industrial scale is described in reviews [2,3].

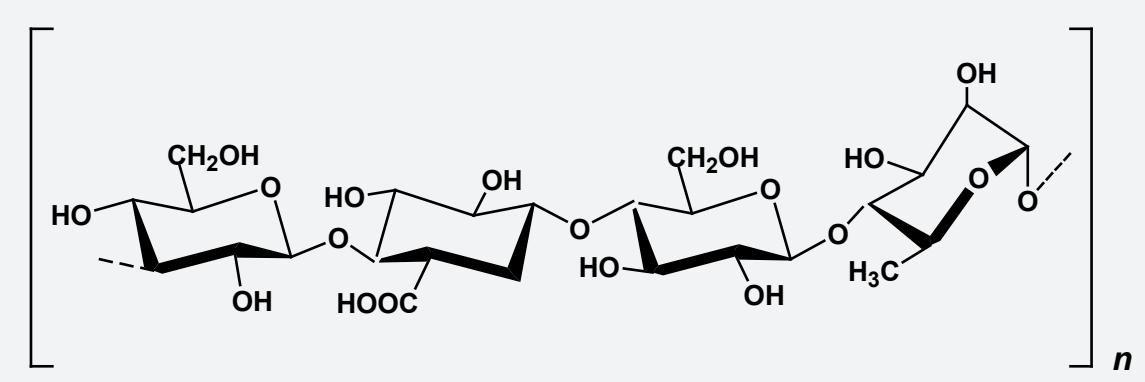

Figure 1: Structure of the repeating monomer unit of gellan.

So far most of the studies have been focused on the application of gellan as a food ingredient. Last year's however, the applicability of gellan gum in EOR was demonstrated [4-12]. Due to the unique structure and beneficial properties, gellan is currently described as a potent multifunctional additive for various pharmaceutical products. Specific gelling properties in different media led to the development of controlled release forms based on gellan. Various formulations have been studied 
including oral, ophthalmic, nasal and other [13,14]. Recent report [13] suggests that gellan-based materials can also be used in regenerative medicine, stomatology or gene transfer technology. Gellan gum-based hydrogels exhibit excellent in vivo and in vitro biocompatibility [15], tunable physical mechanical and injectable properties [16-18] for application in regeneration of cartilage [16,17], tissue engineering [19], cell encapsulation [20], nucleus pulposes regeneration [21]. Recent progress in the design of multi-functional hydrogels with participation of gellan gum in the context of biomedical engineering and regenerative medicine is discussed and summarized in recent review [22]. In spite of a wide application of gellan in medicine, pharmacy and biotechnology it is noteworthy that the gellan based anticancer formulations have not been described.

\section{Conformational and phase behavior of gellan gum in response to external stimuli}

Table 1 represents the chemical and physical properties of gellan. The native gellan is composed of high acyl and low acyl precursors [23]. The main difference between them is that the high acyl gellan contains two acyl substituents: acetyl and L-glyceril [24]. Low acyl gellan is obtained by removal of the acyl residues by alkaline hydrolysis [25]. Differences between highand low acyl gellan are summarized in Table 2 [26]. Authors $[1,27]$ comprehensively reviewed the structure, conformation, gelation, topology, rheology, and application aspects of gellan. The coil-helix conformational and sol-gel phase transitions of gellan gums induced by temperature, salt addition, $\mathrm{pH}$ change etc. became the main subject of many studies [28-33]. A series of publications cover formation of interpenetrating networks with participation of gellan and natural polymers [34-42]. It is commonly accepted [43-51] that gellan gum exhibits a conformational change from the disordered state (single chain) to the ordered state (double helix) with decreasing of temperature, and the gelation is considered to be mediated by the double-helix formation and the association of such helices, which is enhanced by the presence of mono- and divalent alkaline and alkaline earth cations [52-55] (Figure 2).

Table 1: Chemical and physical properties of gellan.

\begin{tabular}{|c|c|}
\hline Property & Description \\
\hline Appearance & off-white powder \\
\hline Types & native, deacetylated, clarified (i.e., filtered deacetylated gum) \\
\hline Molecular weight & $\begin{array}{l}\text { varies within a very wide range } \\
\sim 500,000 \\
>70,000 \text {, with } 95 \% \text { above } 500,000\end{array}$ \\
\hline Solubility & $\begin{array}{l}\text { soluble in hot or cold deionized water } \\
\text { soluble in water; insoluble in ethanol }\end{array}$ \\
\hline Viscosity & $\begin{array}{l}\text { can exhibit high viscosity in solution } \\
\text { high-acyl gellan gum is viscous; deacylated gellan gum (treated with an alkali) has relatively low solution viscosity } \\
\text { cold dispersions of native gellan gum provide extremely high viscosities, and the solutions are highly thiotropic; the viscosity } \\
\text { decreases with heating as the gum hydrates; hot native gum solutions are more viscous than deacylated gellan gum solutions }\end{array}$ \\
\hline Gelling property & forms a weak gel in water in its native state, but forms a rigid gel after treatment with an alkali \\
\hline Ionic nature & anionic \\
\hline Hydration & $\begin{array}{l}\text { native (acylated) gellan gum will swell in deionized water forming a very thick particulate system, and the hydration } \\
\text { temperature is } \\
\text { reached at } \sim 70^{\circ} \mathrm{C} \text {; the swelling behavior and hydration temperature is altered in the presence of ions } \\
\text { deacylated gum will only partially hydrate in cold deionized water, with hydration occurring with a heated deionized water } \\
\text { temperature of } \sim 70^{\circ} \mathrm{C} \text {; also, hydration is poor in mildly acidic conditions and in the presence of divalent ions }\end{array}$ \\
\hline
\end{tabular}

Table 2: Comparison of the properties of high- and low acyl gellan.

\begin{tabular}{|c|c|c|c|}
\hline Type of Gellan & Molecular Weight & Solubility & Set Temperature \\
\hline High acyl gellan & $(1-2) \times 106$ Daltons & Hot water & Hot or cold water \\
\hline Low acyl gellan & $(2-3) \times 105$ Daltons & $70-80^{\circ} \mathrm{C}$ & $30-50^{\circ} \mathrm{C}$ \\
\hline
\end{tabular}




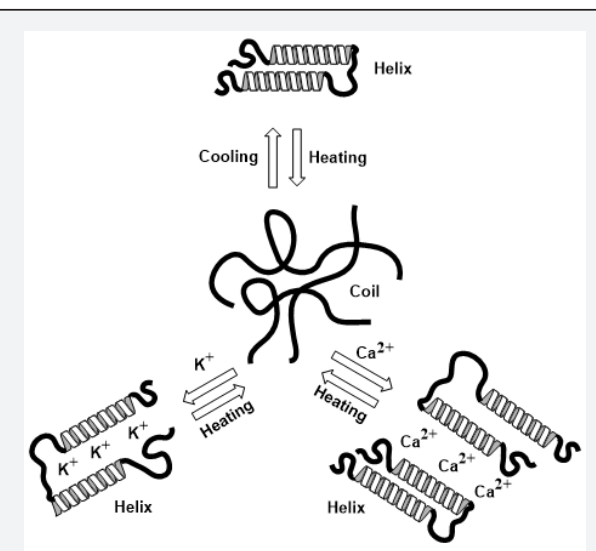

Figure 2: Schematic representation of transformation of gellan gum in aqueous solution from the coil to helix conformation as a function of temperature and salt addition.

As gellan molecules contain the carboxyl groups in the repeating unit, the gelation of gellan is remarkably enhanced by the addition of cations in aqueous solutions. It has been established that the extent of aggregation and effectiveness in promoting gel formation by addition of ions follows this order: $\mathrm{Cs}^{+}>\mathrm{Rb}^{+}>\mathrm{K}^{+}>\mathrm{Na}^{+}>\mathrm{Li}^{+}$. This sequence follows the Hofmeister series and agrees well with increasing of the ionic radius of cation species. The higher effectiveness of divalent cations in comparison with monovalent ones may beattributed to additional crosslinking of gellan chains due to cooperative binding (or "bridging") of the divalent cations between glucuronate residues according to their ionic radii. Divalent cations seem to bind directly to gellan macromolecules to form aggregates of gellan helices with the effectiveness of $\mathrm{Ca}^{2+}>\mathrm{Mg}^{2+}$ [56-60]. The main difference between the monovalent and divalent cations is that the monovalent cations shield the electrostatic repulsion between the COO- while the divalent cations, rather than by suppressing electrostatic repulsion, form interchain ionic bonds with carboxylic groups of the glucuronic acid units resulting in the aggregation of the double helices $[55,56]$. As for the divalent cations, they do not appear to obey the Hofmeister series and the order among the divalent cations is more difficult to rationalize. Gellan salts with the monovalent cation, such as lithium or potassium, form stiff gels and that with divalent cation, $\mathrm{Ca}^{2+}$, make a more rigid gel. The mechanism for conformational change of gellan in the presence of mono- and divalent cations can be represented as shown in Figure 2 [61]. $\mathrm{K}^{+}$accelerates the formation of cooperative hydrogen bonds between gellan molecules by the charge-shielding effect and hydrogen bonds reinforces the double-helices and their aggregates. $\mathrm{Ca}^{2+}$ forms ionic bonds between carboxylic groups of gellan in addition to hydrogen bonds and leads to the continuous structural change depending on concentration of the divalent cations.

\section{Immobilization of anticancer drugs within gellan hydrogel matrix}

Recently authors [62,63] developed gellan-based nanohydrogel systems to deliver multiple drugs: prednisolone and paclitaxel. Prednisolone was chemically linked to the carboxylic groups of gellan while placitaxel was physically entrapped into gel marix. The synergistic anti-inflammatory and anti-cancer effect were reached with respect to malignant cells and tumor inflammatory components.

The kinetics of prednisolone release from gellan hydrogel was measured with respect to NIH/3T3 cells. Figure 3 shows the intracellular release kinetics of gellan-immobilized prednisolone from the gel matrix. It is seen that $40 \%$ of total prednisolone is delivered during $30 \mathrm{~min}, 70 \%$ after $1 \mathrm{~h}$ and $100 \%$ drug delivery after $24 \mathrm{~h}$. It is suggested that the release of prednisolone from gellan-based nanohydrogel is hydrolysis of ester bonds between prednisolone and gellan gum by esterase. Immobilized within gellan nanohydrogel prednisolone exhibits a core-shell structure and allows solubilizing up to $40 \%$ water-insoluble drug paclitaxel in hydrophobic environment. The main role of paclitaxel is disrupting of the dynamic equilibrium within the microtubule system and inhibiting the cell replication. The cell-killing drug formulation consisted of gellan-immobilized prednisolone with loaded paclitaxel. The latter released from gellan-prednisolone nanohydrogel kills the cancer cells with higher efficiency (56.1 $\pm 0.8 \%$ cell viability) than free drug (91.6 \pm 3.5 cell viability) especially at lower concentration (3nM) (Figure 4).

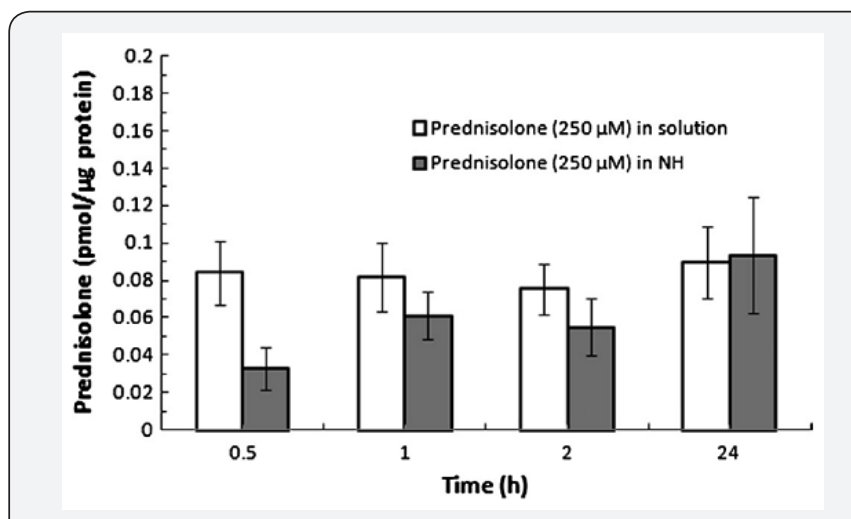

Figure 3: Time-dependent release profile of intracellular prednisolone in $\mathrm{NIH} / 3 \mathrm{~T} 3$ cells in aqueous solution and in nanohydrogel [62].

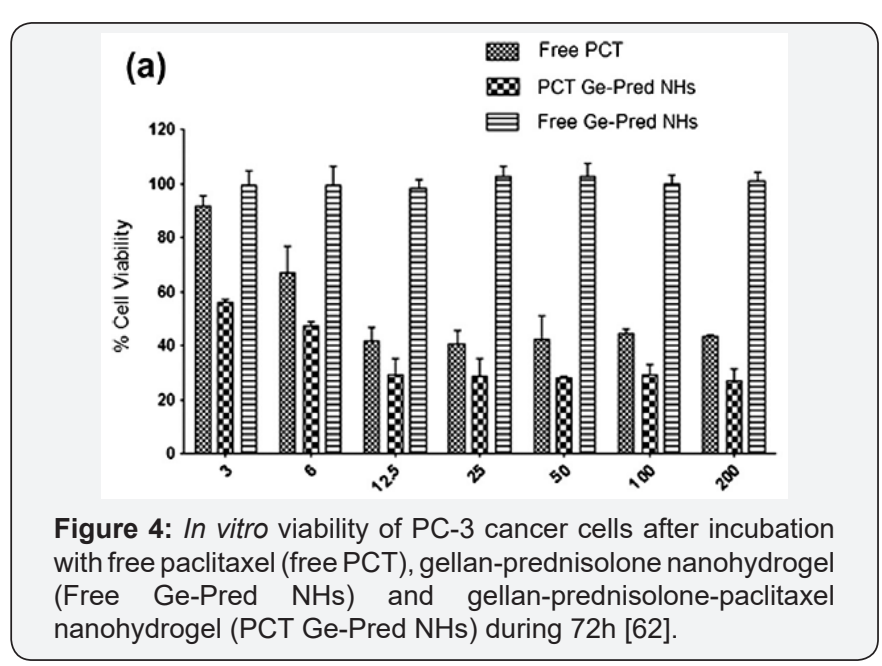


The cell killing effect of gellan-prednisolone-paclitaxel nanohydrogel was also tested with respect to A2780, MDAMB-231 and Skov-3 cells. Thus gellan-immobilized antiinflammatory and anti-cancer drugs can be effective for treatment of malignant and inflammatory cells involved into tumor microenvironment. Analgesic, antipyretic and antiflammatory drug-diclofenac sodium was immobilized into the matrix of polymethacrylamide-grafted-gellan gum and its sustained in vitro release kinetics was studied [64]. It was shown that the diclofenac sodium releases over a period of $8 \mathrm{~h}$ and the release profile is described by Higuchi square root kinetic model and release mechanism is governed by Fickian diffusion.

\section{Gellan gum immobilized gold nanoparticles for treatment of cancer cells}

It is well known that cancer is one of the leading causes of mortality in the modern world, with more than 10 million new cases every year. Targeting nanoparticles that selectively recognize and destroy cancer cells in the body remain key concept in nanomedicine [65-67]. According to literature survey of authors [68] only 7 out of 1000 administered nanoparticles are applicable in a mouse model limiting their clinical translation. Authors [69] concisely highlighted the current state and recent advances of stimuli-responsive polymers commonly employed in oncology applications.
Gold nanoparticles (AuNPs) with controlled geometrical, optical, and surface-chemical properties are the priority research of intensive studies and applications in cancer diagnosis, treatment and as drug delivery system (DDS) [70]. The effectiveness of many anticancer drugs is limited due to the inability to reach the target site in sufficient concentrations and efficiently exert the pharmacological effect without causing irreversible unwanted injury to healthy tissues and cells. The cellular uptake and toxicity of AuNPs stabilized by gellan gum (GG-AuNPs) was studied on mouse embryonic fibroblast cells, NIH 3T3 and human glioma cell line LN-229 [71]. It was shown that in the cancerous cells the GG-AuNPs were localized mainly in the cytoplasm and perinuclear region of the cells. Oral administration of GG-AuNPs did not cause any toxicity in rats for 28 days and was no any significant difference in hematological, biochemical and histopathology of organs demonstrating potential of GG-AuNPS as DDS.

The AuNPs stabilized by gellan gum was loaded by doxorubicin hydrochloride (DOX) one of the potential and wellknown anticancer drugs [72] was conjugated with sophorolipid (SL) [73] and their cytotoxicity were evaluated with respect to human glioma cell line LN 229 and human glioma stem cell line HNGC-2 (Figures 5 \& 6).

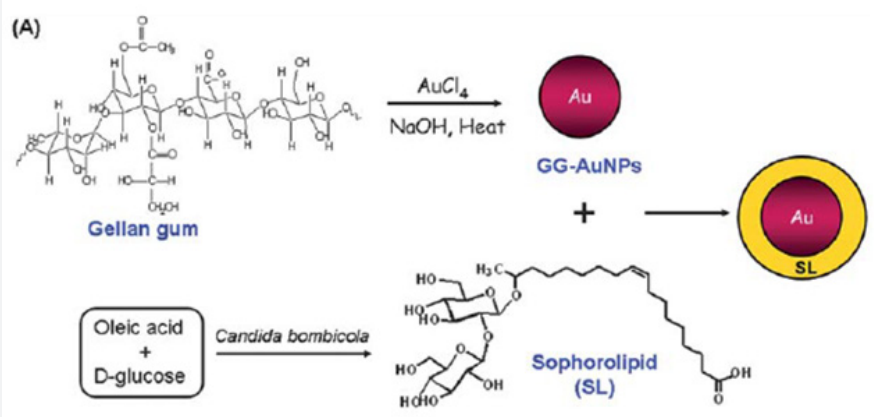

Figure 5: Synthesis of gellan gum reduced and stabilized AuNPs (GG-AuNPs) and sophorolipid-conjugated GG-AuNPs [72].

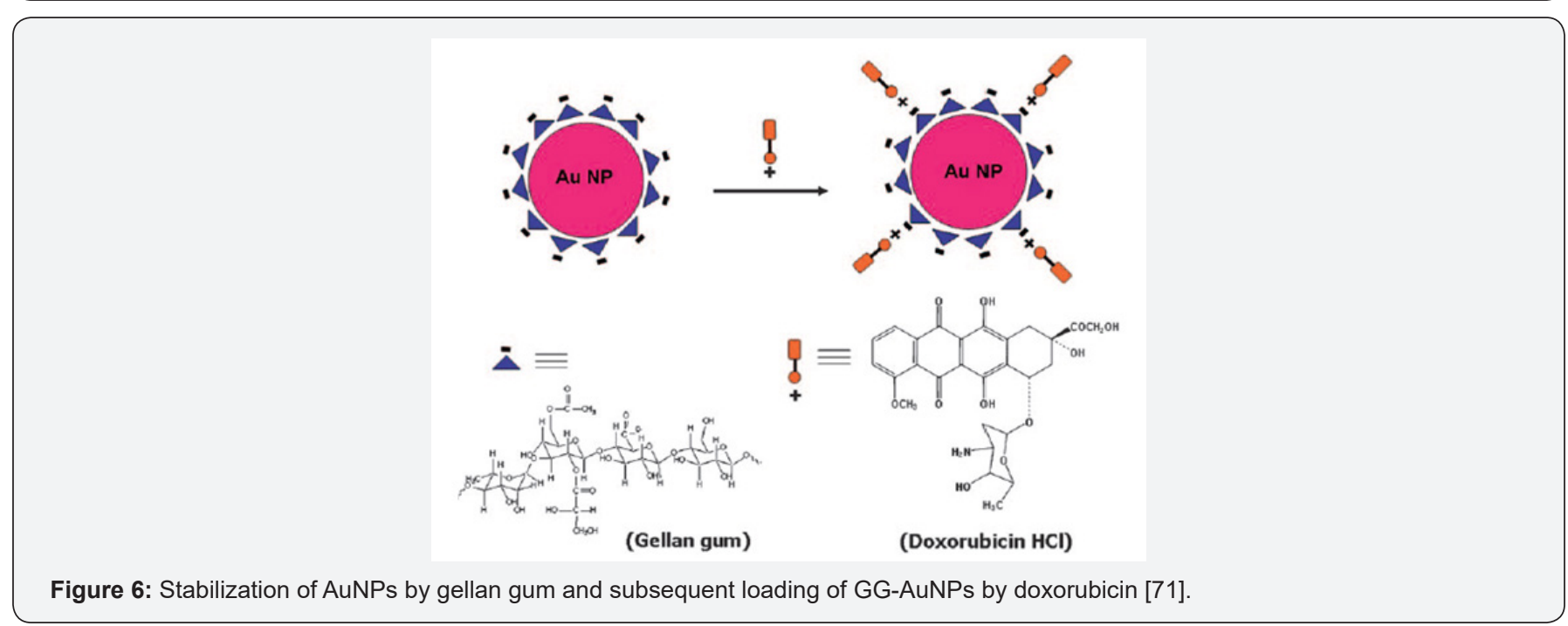


Both SL-conjugated and DOX-loaded gellan gum containing AuNPs exhibited increased effectiveness against glioma tumors. The same authors [74] studied the antibacterial activity of the dispersions of silver nanoparticles (AgNPs) stabilized by gellan gum (GG-AgNPs), the cytotoxicity of GG-AgNPs against mouse embryonic fibroplast cells NIH $3 \mathrm{~T} 3$ and also evaluated the in vitro diffusion of AgNPs dispersions/gels across rat skin. The results show that GG capping effectively passivates the AgNPs and does not display any cytotoxicity against NIH 3T3 and exhibits eligibility for topical treatments.

Photothermal damage of cells is currently one of the most promising research avenues in the treatment of cancer and infectious diseases. The essence of this phenomenon is as follows: AuNPs have an absorption maximum in the visible or near-IR (NIR) region and get very hot when irradiated with corresponding light. If, they are located inside or around the target cells (which can be achieved by conjugating gold nanoparticles to antibodies or other molecules), these cells die. The revolution in thermal cancer therapy is associated with 20-40nm AuNPs that convert the $20 \mathrm{~ns}$ laser irradiation $(514 \mathrm{~nm})$ to local heat (up to $40-45^{\circ} \mathrm{C}$ ), and selectively kill the cancer cells (Figure 7). This method called plasmonic photothermal therapy (PPTT) [75] has extensively been researched and used for biomedical application [76]. The PPTT has much potential in diagnosis, treatment and evolution of diseases, in particular cancer [77]. In recent review [78] the advancements of plasmonic nanoparticles and films in the field of biomedicine was overviewed.
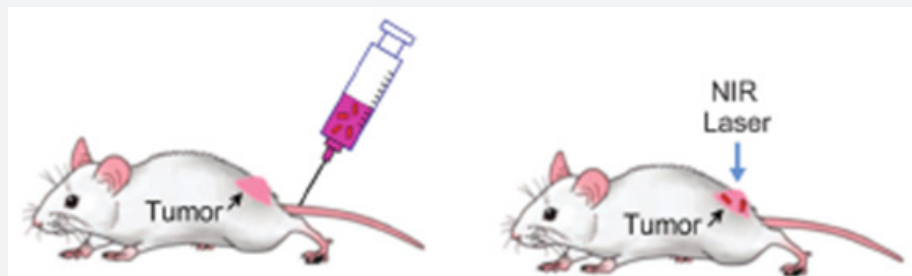

Figure 7: Schematically representation of tumor treatment by NIR laser irradiation.

Among the numerous nanomaterials the best one is gold nanoparticles (AuNPs) because of their biocompatibility, low toxicity, ability to absorb in visible or NIR region, excellent photostability, and availability in various morphologies [79]. Among the gold nanoparticles the gold nanoshells [80] and nanorods (AuNRs) [81] are especially suitable for PPTT due to their tunable longitudinal plasmon band in the NIR region [82].

Small spherical AuNPs exhibit poor NIR absorption, therefore nanoaggregates, nanoshells, nanorods and nanomatryoshkas stabilized by functional polymers are suitable for PPTT [78]. Gellan gum coated gold nanorods (GG-AuNRs) was fabricated by authors [83] and used for intracellular drug delivery and imaging. The preparation strategy of AuNRs includes several steps: at first the fine dispersed AuNRs is synthesized by a seed-mediated growth method using cationic surfactant cetyltrimethylammonium bromide (CTAB) as surface passivant [84], then the layer-by-layer (LBL) technique is used for coating, and finally AuNRs are coated by gellan gum (Figure 8).
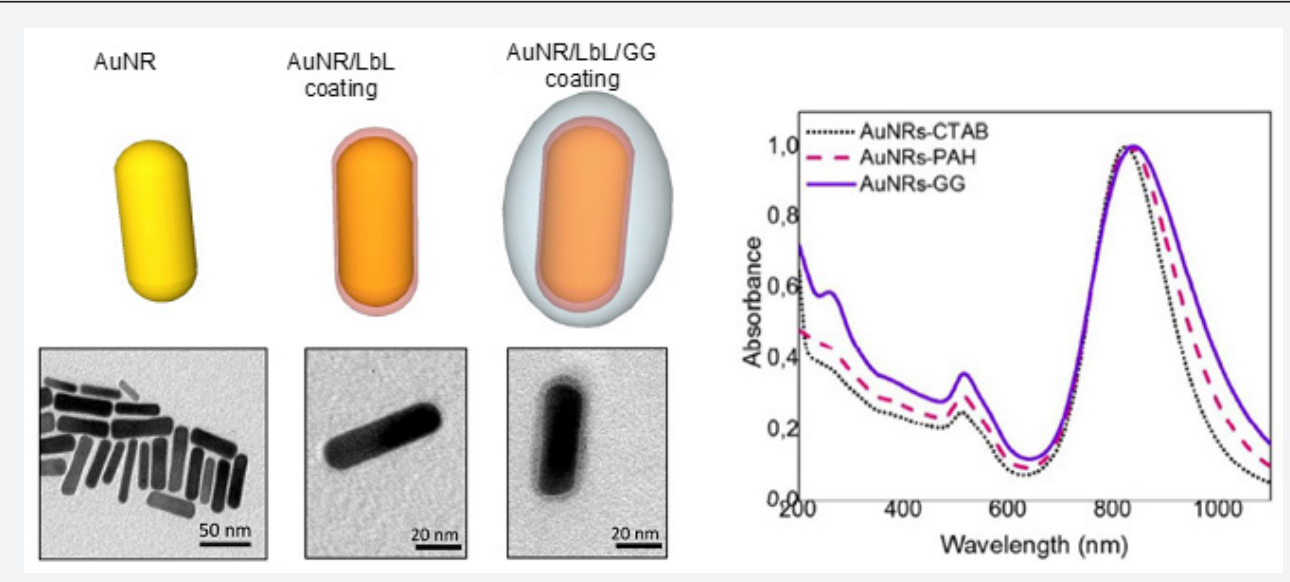

Figure 8: Covering and TEM images of AuNRs by layer-by-layer coatings (AuNRs/LbL) and coating by gellan gum of $A u N R s / L b L$ (left) and visible spectra of AuNRs-CTAB, AuNRs-CTAB-LbL, AuNRs-GG (right) [84].

The direct use of as-prepared AuNRs with biological materials is highly limited because the cytotoxicity of CTAB is high and can lead to cell death. The successive deposition of poly (acrylic acid), poly (allylamine hydrochloride) and GG allows the 
formation of GG shell with nanometric size around individual AuNRs. The cytotoxicity and osteogenic ability of gellan-coated AuNRs was tested with respect to SaOS-2 (Sarcoma osteogenic), a human osteoblast-like cell line commonly used as osteoblastic model [85]. It was found that AuNR-GG were not cytotoxic after 14 days of culturing and were localized inside lysosomes. The images in Figure 9 show that AuNRs-GG is aggregated within multilammelar vesicles identificed as lysosomes.
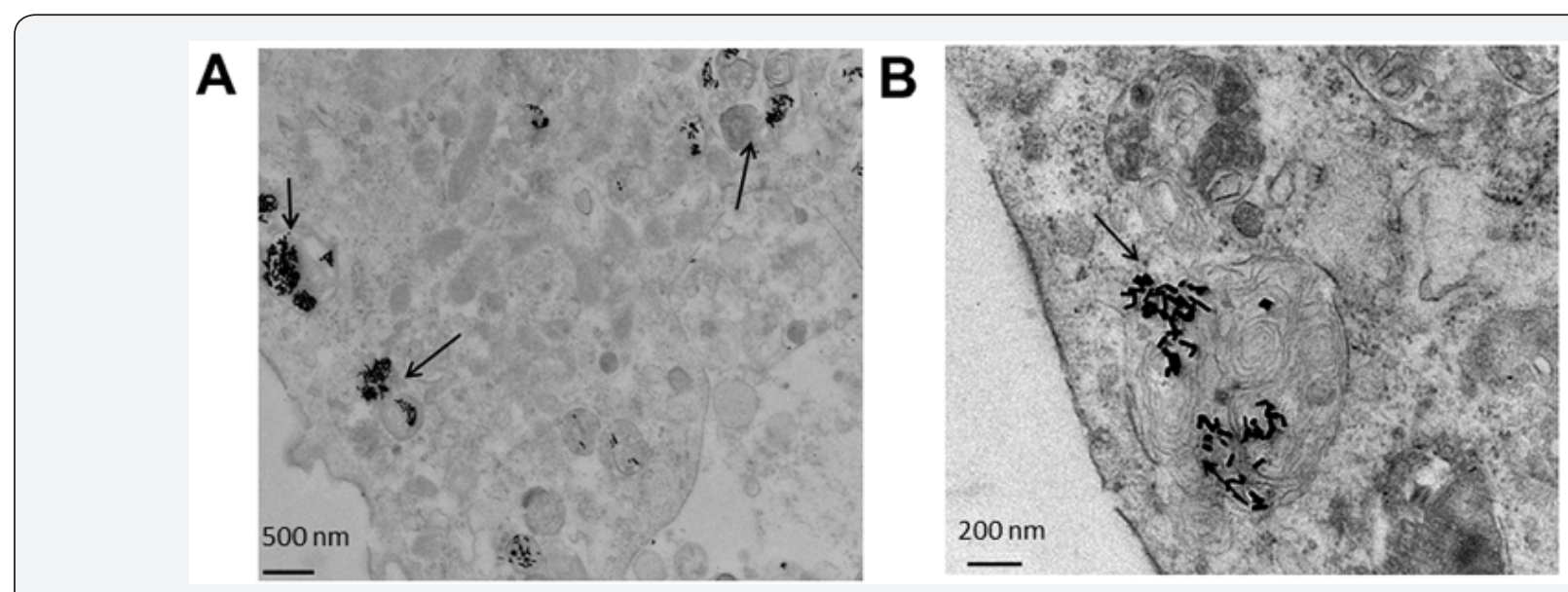

Figure 9: TEM images of SaOS-2 cytoplasm after 14 days of culture with AuNRs-GG. Black arrows point AuNRs-GG clusters [83].

NIR lasers are selected due to higher penetration of human tissue resulting in minimal damage. In vitro experiments show that heating of tumor tissues is observed in the presence of NIR-exposed AuNRs, however laser irradiation in the absence of AuNRs causes negligible damage of healthy tissues [78]. Without coating by biocompatible polymers, AuNRs cannot infiltrate the blood vessels and therefore their concentration increases in plasma. In vivo tumor ablation requires a tissue temperature of around $48-50^{\circ} \mathrm{C}$ for successful operation.
Magnetic nanoparticles coated by GG exhibited low cytotoxicity with potential drug delivery applications [86]. Apart from gellan both natural and synthetic polymers can be used for stabilization and coating of AuNRs. Absorption spectra of polymer-coated AuNRs are in NIR region and equal to $770 \mathrm{~nm}$ (Figure 10a). According to TEM measurements the average size of AuNRs covered by poly(vinylcaprolactame) (PVCL) is < 100nm (Figure 10b).

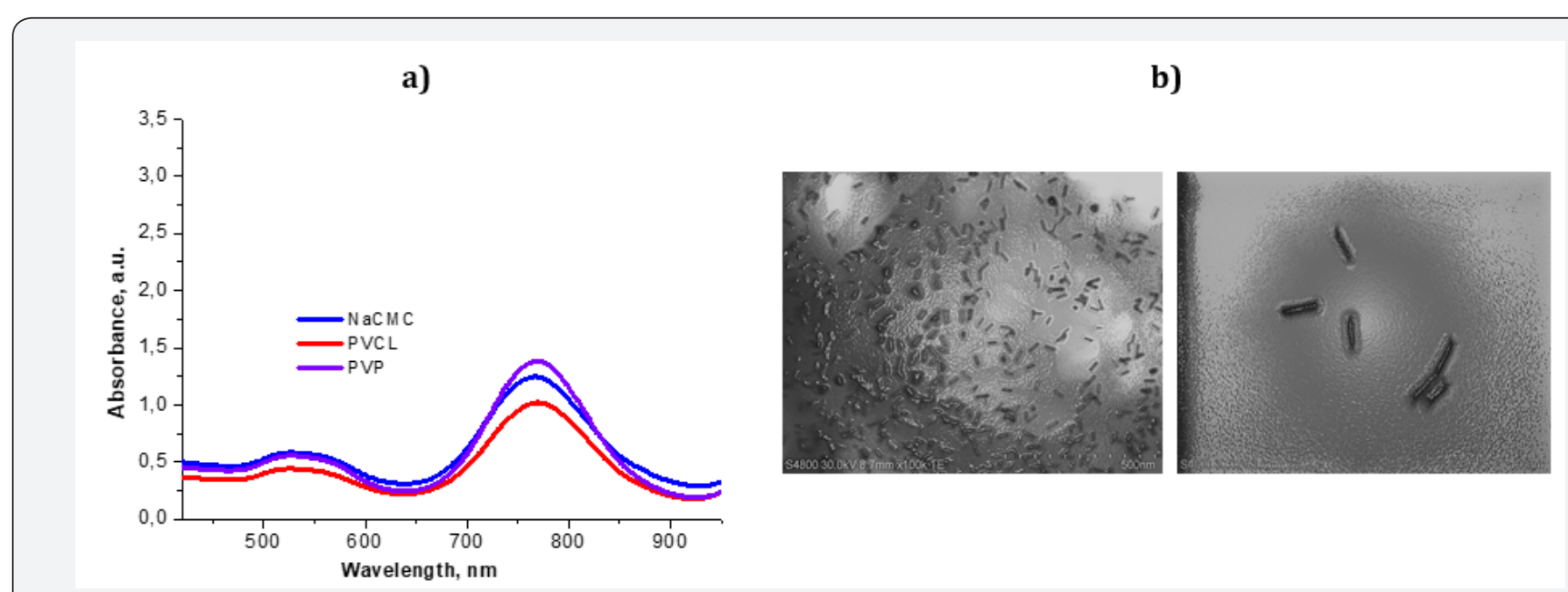

Figure 10: a) UV-Visible spectra of AuNRs stabilized by sodium salt of carboxymethylcellulose (NaCMC), poly(vinylcaprolactame) (PVCL), poly(N-vinylpyrrolidone) (PVP); b) TEM images AuNRs stabilized by PVCL.

Multilayered $\mathrm{Au}$ nanoparticles $\left(\mathrm{Au} / \mathrm{SiO}_{2} / \mathrm{Au} \sim 90 \mathrm{~nm}\right)$ called as nano-matryoshkas ("matryoshka" is Russian nesting doll) was tested against triple negative breast cancer (TNBC) tumors [87]. In vivo injection of Au nanomatryoshkas and NIR treatment (2W.cm ${ }^{-2}$ for $5 \mathrm{~min}$ ) of TNBC tumor-bearing mice show health improvement and complete recovery for two months (Figure 11a). In contrast, NIR treatment of TNBC in saline water without $\mathrm{Au}$ nano-matryoshkas considerably increases the size of tumor for 18 days (Figure 11b). 

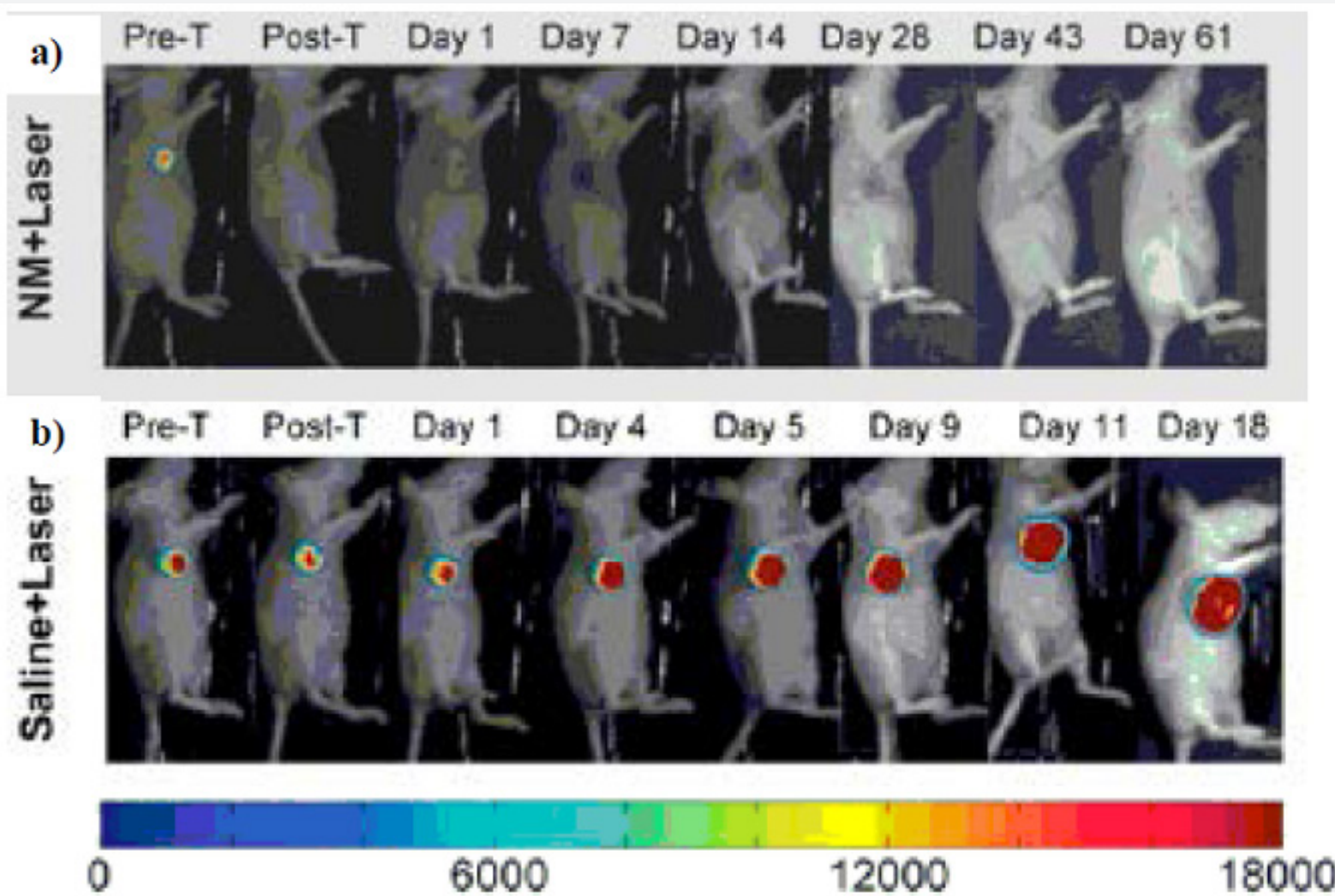

Figure 11: Evaluation of tumor response to photothermal therapy by bioluminescence imaging. The bioluminescence signal is generated only in living cancer cells as a result of luciferase activity [87].

The Au-based nanomaterials have failed in clinical trials as PPTT agents. The further development of PPTT and its acceptance in actual clinical practice depends on success in solving many problems, the most important ones being

a) The choice of nanoparticles with optimal optical properties,

b) The enhancement of nanoparticle accumulation in tumors and the lowering of total potential toxicity, and

c) The development of methods for the delivery of optical radiation to the targets and the search for alternative radiation sources combining high permeability with a possibility of heating AuNPs.

The selection criteria of PPTT depend on

a) The ability of gold nanoparticles to absorb in the nearIR region;

b) Size of nanoparticles (usually less than 100nm);

c) Low toxicity (in terms of excluding or replacement of toxic $\mathrm{CTAB}$ );

d) Good biocompatibility and easy biodegradability of polymeric coatings used for entrapment of gold nanoparticles. Moreover, the aggregated AuNPs should be disintegrated and removed from the organs and not cause tissue damage or metal toxicity.

It is expected that in near future the priority research will be focused on probing the fundamental interactions of nanoparticles with organs and tissues that accumulate, sequester or eliminate nanoparticles (such as liver, spleen and kidney), as well as the interactions between nanoparticles and tumors with respect to the physico-chemical properties of the nanoparticles.

\section{Conclusion}

The unique properties of gellan gum, in particular, biocompatibility, low toxicity, biodegradability, commercial availability and low cost argue the successful application of this class of polysaccharide in biomedicine, pharmacy and bioand nanotechnology. The ability of gellan to undergo coil-helix conformational, sol-gel phase transitions, and stimuli-sensitive character of macromolecules to response temperature, $\mathrm{pH}$, salt addition, addition of organic ions and molecules open new perspectives to design drug delivery systems. Anticancer drugs and gold nanoparticles immobilized within gellan gel matrix is effective for treatment of cancer cells. It is expected that in near future the priority research will be focused on probing the fundamental interactions of nanoparticles with organs and tissues that accumulate, sequester or eliminate nanoparticles 
(such as liver, spleen and kidney), as well as the interactions between nanoparticles and tumors with respect to the physicochemical properties of the nanoparticles. For the successful application of nanoparticles there should be a coordinated research program to establish correlations between the particle parameters (size, shape, and functionalization with various molecular probes), the experimental parameters (model; doses; method and time schedule of administration; observation time; organs, cells and subcellular structures examined; etc.), and the observed biological effects.

\section{Acknowledgements}

This work was supported by Sichuan Science and Technology Program (No. 2018HH0024, 2018-2019) and carried out in the frame of collaborative research project entitled "Fabrication and controlled drug release of thermosensitive gradient nanocomposite hydrogels" between College of Chemistry, Sichuan University, China and Institute of Polymer Materials and Technology, Kazakhstan.

\section{References}

1. Morris ER, Katsuyoshi N, Rinaudo M (2012) Gelation of gellan A review. Food Hydrocolloids 28(2): 373-411.

2. Bajaj IB, Survase SA, Saudagar PS, Singhal RS (2007) Gellan gum: Fermentative production, downstream processing and applications (Review). Food Technol Biotechnol 45(4): 341-354.

3. Giavasis I, Harvey LM, Mc Neil B (2000) Gellan gum. Critical Reviews in Biotechnology 20: 177-211.

4. Kudaibergenov S, Adilov Zh, Nuraje N, Sagindykov A, Tatykhanova G, et al. (2012) Laboratory test for enhanced oil recovery with gellan. International Journal of Biology and Chemistry 4: 58-68.

5. Ibragimov R, Gusenov I, Tatykhanova G, Adilov Zh, Nurxat Nuraje, et al. (2013) Study of gellan for polymer flooding. Journal of Dispersion Science and Technology 34: 1-8.

6. Gussenov I Sh, Ibragimov R Sh, Kudaibergenov SE, Abilkhairov DT, Kudaibergenov DN (2014) Application of polymer gellan for injectivity profile leveling. SPE Annual Caspian Conference and Exhibition 1-7.

7. Kudaibergenov S, Nuraje N, Adilov Zh, Abilkhairov D, Ibragimov R, et al. (2015) Plugging behavior of gellan in porous saline media. Journal of Applied Polymer Science 132(2): 41256.

8. Kudaibergenov SE, Gussenov I Sh, Zhappasbayev B Zh, Shakhvorostov AV (2015) Application of polymer flooding technology for enhanced oil recovery. Chemical Bulletin of Kazakh National University 4(80): 74-80.

9. Nurakhmetova Zh, Gussenov I Sh, Tatykhanova GS, Kudaibergenov SE (2015) Behavior of gellan in aqueous-salt solutions and oilfield saline water. Chemical Bulletin of Kazakh National University 3(79): 35-40.

10. Kudaibergenov SE, Tatykhanova GS, Sigitov VB, Nurakhmetova ZA, Blagikh EV, et al. (2016) Physico-chemical and rheological properties of gellan in aqueous-salt solutions and oilfield saline water. Macromol Symp 363(1): 20-35.

11. Gussenov I, Zhappasbayev B, Kudaibergenov S (2017) Permeability reduction of heterogeneous oil reservoirs by brine-triggered gellan gel. Journal of Nanoscience and Nanotechnology 17(12): 9198-9201.

12. Zh Nurakhmetova, I Gussenov, $\mathrm{V}$ Aseyev, $\mathrm{V}$ Sigitov, $\mathrm{S}$ Kudaibergenov (2018) Application of sol-gel transition of gellan and xanthan for enhanced oil recovery and as drilling fluids. Journal of Chemical Technology and Metallurgy 53(1): 68-78.

13. Osmalek Tomasz, Froelich Anna, Tasarek Sylwia (2014) Application of gellan gum in pharmacy and medicine. International Journal of Pharmaceutics 466(1-2): 328-340.

14. Gan L, Gan Y, Zhu X, Zhu J (2009) Novel microemulsion in situ electrolyte-triggered system for ophthalmic delivery of lipophilic cyclosporine A: In vitro and in vivo results. International Journal of Pharmaceutics 365(1-2): 143-149.

15. Silva Correa J, Zavan B, Vindigni V, Silva TH, Oliveira JM, et al. (2013) Biocompatibility evaluation of ionic- and photo-crosslinked methacryalted gellan gum hydrogels: In vivo and in vitro study. Adv Healthc Mater 2(4): 568-575.

16. Gong J, Wang C, Lai RC, Su K, Zhang K, et al. (2009) An improved injectable polysaccharide hydrogel: Modified gellan gum for long-term cartilage regeneration in vitro. J Mater Chem 19: 1968-1977.

17. Oliveira JT, Gardel LS, Rada T, Martins L, Gomes ME, et al. (2010) Injectable gellan gum hydrogels with autologous cells for the treatment of rabbit articular cartilage defects. J Orthop Res 28(9): 1193-1199.

18. Coutinho DF, Sant S, Shin H, Oliveira JT, Gomes ME, et al. (2010) Modified gellan gum hydrogels with tunable physical and mechanical properties. Biomaterials 31(2): 7494-7502.

19. Silva-Correa J, Oliveira JM, Caridade SG, Oliveira JT, Sousa RA, et al (2011) Gellan gum-based hydrogels for intervertebral disc tissue engineering applications. J Tissue Eng Regen Med 5(6): e97-e107.

20. Tsaryk R, Silva Correia J, Oliveira JM, Unger RE, Landes C, et al. (2017) Biological performance of cell-encapsulated methacrylated gellan gum-based hydrogels for nucleus pulposes regeneration. J Tissue Eng Regen Med 11(3): 637-648.

21. SilvaCorrea J, Miranda Goncalves V, Salgado AJ, Sousa N, Oliveira JM, et al. (2012) Angiogenic potential of gellan-gum-based hydrogels for application nucleus pulposes regeneration: In vivo study. Tissue Eng Part A 18(11-12): 1203-1212.

22. Hacker MC, Nawaz HA (2015) Multi-functional macromers for hydrogel design in biomedical and regenerative medicine. Int J Mol Sci 16(11): 27677-27706.

23. 0 Neill MA, Selvendran RR, Morris VJ (1983) Structure of the acidic extracellular gelling polysaccharide produced by Pseudomonas elodea. Carbohydr Res 124(1): 123-133.

24. Chandrasekaran R, Radha A, Thailambal VG (1992) Roles of potassium ions, acetyl and L-glyceril groups in native gellan double helix: An X-ray study. Carbohydr Res 224: 1-17.

25. Kang KS, Veeder GT, Mirrasoul PJ, Kaneko T, Cottrell IM (1981) Agarlike polysaccharide produced by a pseudomonas species: production and basic properties. Appl Environ Microbiol 43950: 1086-1091.

26. Jansson PE, Lindberg B, Sandford PA (1983) Structural studies of gellan gum an extracellular polysaccharide elaborated by Pseudomonas elodea. Carbohydrate Research 124(1): 135-139.

27. Morris E, Katsuyoshi N, Rinaudo M (2012) Gelation of gellan A review. Food Hydrocolloids 28(2): 373-411.

28. Fukada H, Takahashi K, Kitamura S, Yuguchi Y, Urakawa H, et al. (2002) Termodynamics and structural aspect of the gelling process in the gellan gum/metal salt aqueous solutions. Journal of Thermal Analyss Calorimetry 70(3): 797-806.

29. Jennifer F, Robin H, Fotios S, Ian T (2014) Self- structuring foods based on acid-sensitive low and high acyl mixed gellan systems to impact on satiety. Food Hydrocolloids 35: 522-530. 
30. Mariella D, Pasquale D, Vittorio C (1999) Solution and gelling properties of gellan benzyl esters. Macromolecules 32(21): 7109-7115.

31. Matsukawa S, Huang Z, Watanabe T (1999) Structural change of polymer chains of gellan monitored by circular dichroism. Progress in Colloid and Polymer Science 114: 92-97.

32. Miyoshi E, Nishinari K (1999) Non-Newtonian flow behavior of gellan gum aqueous solutions. Progress in Colloid and Polymer Science 277(8): 727-734.

33. Tuan Chew T, Wan Teck F, Min Tze L, Azhar M (2014) Comparative assessment of rheological properties of gelatin or gellan in maize starch egg white composite gels. Journal of King Saud UniversityScience 26(4): 311-322.

34. Amici E, Clark AH, Johnson NB, Normand V (2000) Interpenetrating network formation in gellan-agarose gel composites. Biomacromolecules 1(4): 721-729.

35. Clark AH, Eyre SCE, Ferdinando DP (1999) Interpenetrating network formation in gellan-maltodextrin gel composites. Macromolecules 32(23): 7897-7906

36. Claudia C, Davide B, Cristina L, Andrea M, Pietro M (2011) Preparation and characterization of new gellan gum and sulphated hyaluronic acid hydrogel designed for epidural scar prevention. Journal of Materials Science-materials in Medicine 22(2): 263-271.

37. Gunning AP, Kirby AR, Ridout MJ, Brownsey GJ, Morris VJ (1996) Investigation of gellan networks and gels by atomic force microscopy. Macromolecules 29(21): 6791-6796.

38. Kousaku O, Masanori Y, Ayako N, Norio N, Hiroyuki Y (2000) Biodegradation of chitosan-gellan and poly(L-lysine)-gellan polyion complex fibers by pure cultures of soil filamentous fungi. Journal of Polymers and the Environment 8(2): 59-66.

39. Mariella D, Pasquale D, Vittorio C, Yoshiaki Y, Hiroshi U, et al. (2001) Synthesis and physicochemical characterization of gellan gels. Macromolecules 34(5): 1449-1453.

40. Popa M, Dumitriu CL, Sunel V (2004) Interpenetrated polymeric networks based on gellan and poly (vinyl alcohol). Polymer-plastic Technology and Engineering 43: 1503-1516.

41. Ramires PA, Milella E (2002) Biocompatibility of poly (vinyl alcohol)hyaluronic acid and poly (vinyl alcohol)-gellan membranes crosslinked by gultaraldehyde vapors. Journal of Materials Science-materials in Medicine 13(1): 119-123.

42. Shipra T, Suvendu B (2011) Aeration of model gels: Rheological characteristics of gellan and agar gels. Journal of Food Engineering 107(1): 134-139.

43. Emako M, Tomohisa T, Peter A, Katsuyoshi N (1996) Effects of sodium chloride and calcium chloride on the interaction between gellan gum and konjac glucomannan. Journal Agricultural Food Chemistry 44(9): 2486-2495.

44. Kanesaka Sh, Watanabe T, Matsukawa Sh (2004) Binding effect of $\mathrm{Cu}^{2+}$ as a trigger on the sol-to-gel and the coil-to-helix transition processes of polysaccharide, gellan gum. Biomacromolecules 5(3): 863-868.

45. Kohei K, Junichi H, Shiro M (2005) Effects of monovalent cation and anion species on the conformation of gellan chains in aqueous systems. Carbohydrate Polymers 61(2): 168-173.

46. Mazen F, Milas M, Rinaudo M (1999) Conformational transition of native and modified gellan. International Journal Biological Macromolecules 26(2-3): 109-118.

47. Natakeyama T, Nakamura K, Takahashi M, Hatakeyama H (1999) Phase transitions of gellan-water systems. Prog Colloid Polym Sci 114: 98101.
48. Takahashi R, Akutu M, Kubota K, Nakamura K (1999) Characterization of gellan gum in aqueous $\mathrm{NaCl}$ solution. Progress in Colloid and Polymer Science 114: 1-7.

49. Yuguchi Y, Urakawa H, Kitamura S, Wataoka I, Kajiwara K (1999) The sol-gel transition of gellan gum aqueous solutions in the presence of various metal salts. Progress in Colloid and Polymer Science 114: 4147.

50. Fukada H, Takahashi K, Kitamura S, Yuguchi Y, Urakawa H, et al. (2002) Termodynamics and structural aspect of the gelling process in the gellan gum/metal salt aqueous solutions. Journal of Thermal Analysis Calorimetry 70(3): 797-806.

51. Ogawa E, Matsuzawa H, Iwahashi M (2002) Conformational transition of gellan gum of sodium, lithium and potassium types in aqueous solutions. Food 16(1): 1-9.

52. Hans G, Olav S (1997) Gelation of Gellan Gum. Carbohydrate Polymers $7(5): 371-393$.

53. Lin D, Xinxing L, Zhen T (2010) Critical behavior at sol-gel transition in gellan gum aqueous solutions with $\mathrm{KCl}$ and $\mathrm{CaCl}_{2}$ of different concentrations. Carbohydrate Polymers 81(2): 207-212.

54. Nickerson M, Paulson A, Speers A (2003) Rheological properties of gellan solutions: effect of calcium ions and temperature on pre-sol formation. Food Hydrocolloids 17: 577-583.

55. Nickerson M, Paulson A, Hallett F (2008) Pre-gel solution properties of gellan polysaccharides: Effect of potassium and calcium ions on chain associations. Food Research International 41(5): 462-471.

56. Juming T, Marvin A, Yanyin Z (1996) Compression strength and deformation of gellan gels formed with mono and divalent cations. Carbohydrate Polymers 29(1):11-16.

57. Masahiko A, Yuko O, Takayuki N (2000) Swelling behavior of covalently cross-linked gellan gels. J Phys Chem 104(29): 6755-6760.

58. Nitta Y, Takahashi R, Nishinari K (2010) Viscoelasticity and phase separation of aqueous $\mathrm{Na}$ type gellan solution. Biomacromolecules 11(1): 187-191.

59. Nishinari K, Miyoshi E (1999) Rheological and thermal properties near the sol-gel transition of gellan gum aqueous solutions. Progress Colloid Polymer Science 114: 68-82.

60. Camelin I, Lacroix C, Paquin C, Prevost H, Cachon R, et al. (1993) Effect of chelatants on gellan gel rheological properties and setting temperature for immobilization of living bifidobacteria. Biotechnology Progress 9(3): 291-297.

61. Matsukawa S, Tang Z, Watanabe T (1999) Hydrogen-bonding behavior of gellan in solution during structural change observed by ${ }^{1} \mathrm{H}$ NMR and circular dichroism methods. Progr Colloid Polym Sci 114: 15-25.

62. D’Arrigo G, Navarro G, Di Meo C, Matricardi P, Torchilin V (2014) Gellan gum nanohydrogel containing anti-inflammatory and anti-cancer drugs: a multi-drug delivery system for a combination therapy in cancer treatment. European Journal of Pharmaceutics and Biopharmaceutics 87(1): 208-216.

63. D’Arrigo G, Di Meo C, Gaucci E, Chichiarelli S, Coviello T, et al. (2012) Self-assembled gellan gum nanohydrogel as a tool for prednisolone delivery. Soft Matter 45(8): 11557-11564.

64. Nandi G, Patra P, Priyadarshini, Kaity S, Ghosh LK (2015) Synthesis, characterization and evaluation of methacrylamide grafted gellan as sustained release tablet matrix. International Journal of Biological Macromolecules 72: 965-974.

65. Peer D, Karp JM, Hong S, Farokhzad OC, Margalit R, et al. (2017) Nanocarriers as an emerging platform for cancer therapy. Nat. Nanotechnol 2: 751-760. 
66. Rao W, Wang H, Han J, Zhao S, Dumbleton J, et al. (2015) Chitosandecorated doxorubicin-encapsulated nanoparticle targets and eliminates tumor reinitiating cancer stem-like cells. ACS Nano 9(6): 5725-5740.

67. Min Y, Caster JM, Eblan MJ, Wang AZ (2015) Clinical translation of nanomedicine. Chem Rev 115(19): 11147-11190.

68. Wilhelm S, Tavares AJ, Dai Q, Ohta S, Audet J, et al. (2016) Analysis of nanoparticle delivery to tumors. Nature Reviews/Materials 1: 1-12.

69. Wagner AM, Spencer DS, Peppas NA (2018) Advanced architectures in the design of responsive polymers for cancer nanomedicine. J App Polym Sci 135(24): 46154

70. Shan J, Tenhu H (2007) Recent advances in polymer protected gold nanoparticles: Synthesis, properties and applications. Chem Commun 44: 4580-4598.

71. Dhar S, Mali V, Bodhankar S, Shiras A, Prasad BLV, Pokharkar V (2011) Biocompatible gellan gum-reduced gold nanoparticles: cellular uptake and subacute oral toxicity studies. J Appl Toxicol 31(5): 411-420.

72. Dhar S, Reddy EM, Pokharkar V, Prasad BLV (2008) Natural gum reduced/stabilized gold nanoparticles for drug delivery formulations. Chem Eur J 14(13): 10244-10250.

73. Dhar S, Reddy EM, Prabhune A, Pokharkar V, Shiras A, et al. (2011) Cytotoxicity of sophorolipid-gellan gum-gold nanoparticle conjugates and their doxorubicin loaded derivatives towards human glioma stem cell lines. Nanoscale 3(2): 575-580.

74. Dhar S, Murawala P, Shiras A, Pokharkar V, Prasad BLV (2012) Gellan gum capped silver nanoparticle dispersions and hydrogels: cytotoxicity and in vivo diffusion studies. Nanoscale 4: 563-567.

75. Huang XH, Jain PK, El Sayed IH, El Sayed MA (2008) Plasmonic photothermal therapy (PPTT) using gold nanoparticles. Lasers in Medical Science 23(3): 217-228.

76. Huang X, Neretina S, El Sayed MA (2009) Gold nanorods: From synthesis and properties to biological and biomedical aplications. Adv. Mater 21(48): 4880-4910.

77. Huang XH., Jain PK, El Sayed IH, El Sayed MA (2007) Gold nanoparticles: interesting optical properties and recent applications in cancer diagnostic and therapy. Nanomedicine 2(5): 681-693.
78. Lim WQ Gao Z (2016) Plasmonic nanoparticles in biomedicine. Nano Today 11(2): 168-188.

79. Jabeen F, Najam ul Haq M, Javeed R, Huck CW, Bonn GK (2014) Aunanomaterials as a superior choice for near-infrared photothermal therapy. Molecules 19(12): 20580-20593.

80. Day ES, Thompson PA, Zhang L, Lewinski NA, Drezek RA, et al. (2011) Nanoshell-mediated photothermal therapy improves survival in a murine glioma model. J Neurooncol 104(1): 55-63.

81. Mackey MA, Ali MRK, Austin LA, Near RD, El-Sayed MA (2014) The most effective gold nanorod size for plasmonic photothermal therapy: Theory and in vivo experiments. J Phys Chem B 118(5): 1319-1326.

82. Huang X, Neretina S, El-Sayed MA (2009) Gold nanorods: From synthesis and properties to biological and biomedical aplications. Adv Mater 21(48): 4880-4910.

83. Viera S, Vial S, Maia F, Carvalho M, Reis RL, et al. (2015) Gellan gumcoated gold nanorods: an intracellular nanosystem for bone tissue engineering. RSC Adv 5: 77996-78005

84. Nikoobakht B, El-Syed MA (2003) Preparation and growth mechanism of gold nanorods (NRs) using seed-mediated growth method. Chem Mater 15(10): 1957-1962.

85. Pautke C, Schieker M, Tischer T, Kolk A, Neth P, et al. Characterization of osteosarcoma cell lines MG-63, Saos-2 and U-2 OS in comparison to human osteoblasts. Anticancer Res 24(6): 3743-3748.

86. Sivakumar B, Aswathy RG, Sreejith R, Nagaoka Y, Iwai S, et al. (2014) Bacterial exopolysaccharide based magnetic nanoparticles: a versatile nanotool for cancer cell imaging, targeted drug delivery and synergistic effect of drug and hyperthermia mediated cancer therapy. J Biomed Nanotechnol 10(6): 885-899.

87. Ayala Orozco C, Urban C, Knight MW, Urban AS, Neumann O, et al. (2014) Au nanomatryoshkas as efficient near-infrared photothermal transducers for cancer treatment: Benchmarking against nanoshells. ACS Nano 8(6): 6372-6381.

\section{Your next submission with Juniper Publishers will reach you the below assets}

- Quality Editorial service

- Swift Peer Review

- Reprints availability

- E-prints Service

- Manuscript Podcast for convenient understanding

- Global attainment for your research

- Manuscript accessibility in different formats

( Pdf, E-pub, Full Text, Audio)

- Unceasing customer service

Track the below URL for one-step submission https://juniperpublishers.com/online-submission.php 